\title{
A pesquisa na encruzilhada: perspectiva afro-brasileira e a pesquisa em educação
}

\section{Research in crossroads: afro-brazilian perspective and research in education}

\author{
João Augusto dos Reis Neto ${ }^{1}$ \\ Maria Jaqueline de Grammont ${ }^{2}$
}

\section{Resumo}

O objetivo deste artigo é discutir de que modo elementos da cosmovisão afro-brasileira, enquanto fontes de conhecimento ancestral e possibilidade epistemológica, podem contribuir para a construção de outras abordagens e metodologias de pesquisa que busquem (se contrapor e) romper com a tradição monológica colonial no campo da pesquisa em educação. Para esta discussão estamos apoiados na perspectiva pós-colonial, a partir do pensamento social afro-latino-americano, nos saberes ancestrais do povo negro, sobretudo naqueles produzidos nas práticas educativas dos terreiros de religião de matriz africana. Além disso, dialogamos com o pensamento de Mikhail Bakhtin. Para isso tomamos a encruzilhada como imagem-conceito e referência epistemológica. A encruzilhada, nesta perspectiva, transcende o signo religioso e se torna uma referência analítica da realidade. Por fim, apresentamos os "círculos dialógicos" como possibilidade metodológica para construção de dados na pesquisa em educação. Com isto, podemos perceber que os círculos dialógicos permitem a construção de uma pesquisa humanizada, calcada na alteridade, no diálogo e no reconhecimento do outro como co-autor do conhecimento e busca romper com um ideal colonizado(r) na construção da pesquisa.

Palavras-chave: Pesquisa em educação. Metodologia da pesquisa. Cultura afro-brasileira. Encruzilhadas.

\begin{abstract}
The objective of this article is to discuss how elements of the Afro-Brazilian worldview, as sources of ancestral knowledge and epistemological possibility, can contribute to the construction of other research approaches and methodologies that seek (to oppose and) break with the colonial monological tradition in the field of education research. For this discussion we are supported in the post-colonial perspective, from the Afro-Latin American social thought, in the ancestral knowledge of the black people, especially in those produced in the educational practices afro-religious. In addition, we dialogue with Mikhail Bakhtin's thinking.

\footnotetext{
1 Mestre em Educação pela Universidade Federal de São João Del Rei e membro do grupo "Laroyê: Culturas Infantis e Pedagogias Descolonizadoras" (UFLA). E-mail: joaoaugusto.reis@ gmail.com.

2 Doutora em Educação, pesquisadora e professora na Universidade Federal de São João Del Rei. E-mail: jaquelinedegrammont@gmail.com.
} 
For this, we take the crossroads as a concept image and an epistemological reference. The crossroads, in this perspective, transcends the religious sign and becomes an analytical reference of reality. Finally, we present "dialogical circles" as a methodological possibility for building data in the research in education. With this, we can see that the dialogic circles allow the construction of a humanized research, based on alterity, in dialogue and in the recognition of the other as a co-author of knowledge and seeks to break with a colonized ideal (r) in the construction of research.

Keywords: Education research. Research methodology. Afro-Brazilian culture. Crossroads.

\section{Introdução}

Ao observarmos as ciências humanas, onde se insere a pesquisa em educação, é possível perceber a hegemonia do pensamento ocidental em nossas pesquisas. Isto é reflexo da prática histórica de dominação, exclusão e silenciamento dos povos considerados subalternos pelos países do Norte $^{3}$, como bem coloca Santos (2007). Nesta perspectiva, o autor considera que o pensamento ocidental é um "pensamento abissal" (SANTOS, 2007, p. 71) e defende que há dois universos político-culturais distintos que são traçados por linhas visíveis e invisíveis. Estes dois universos, nesta lógica, não podem coexistir, e isto inclui suas formas de produzir conhecimento. Historicamente, não houve coexistência, a "ciência ocidental desautorizou e invisibilizou a existência de outras epistemologias para se manter como verdade. Foram articuladas estratégias sistemáticas de eliminação e ocultamento dos saberes produzidos" pelos povos não-europeus (ANDRADE, 2018, p. 77). Com isto, não se pode negar que este é um projeto de poder para a reafirmação de nossa condição colonial, agora contemporizada e atualizada no regime da colonialidade (QUIJANO, 1997).

A colonialidade, de acordo com Quijano (1997), é um regime de poder, gestado no interior do capitalismo, que, em uma de suas manifestações, define quais conhecimentos são válidos e legítimos ao mesmo tempo que condena aqueles que estão "do outro lado" - no Sul - a um verdadeiro epistemicídio, como afirma Sueli Carneiro (2005). A autora formula este conceito a partir da noção de um "assassinato estrutural" dos saberes e conhecimentos dos

\footnotetext{
${ }^{3}$ Quando nos referimos ao Norte estamos falando do eixo Europa-América do Norte, como emprega Santos (2010, p. 13). De modo semelhante, quando falamos em Sul do mundo, nos referimos aos povos que sofreram os horrores da colonização.
} 
povos da diáspora africana. Um dos modos de dominação de um povo é, de acordo com a autora, é destituir-lhe a capacidade de produzir cultura, conhecimento, negando sua legitimidade e, assim, desumanizando-o. Tem sido assim com a história e cultura do povo negro no mundo, especialmente no Brasil que se recusa a tratar das feridas coloniais.

Ao longo dos séculos os negros foram "apagados" de nossa história, foram enclausurados na escravidão, estereotipados a partir de representações folclorizadas de seus modos de vida e religiosidade (OLIVEIRA, 2009). Seus saberes, suas visões de mundo, seus conhecimentos, foram sistematicamente apagados pelo racismo, como pode ser observado nos currículos eurocentrados e racistas que ainda dominam as nossas escolas e atingem, muitas vezes, nossas práticas de pesquisa.

O fato de não nos questionarmos sobre os referenciais teóricos brancos, masculinos, que adotamos "naturalmente" enquanto pesquisadores/as é um sinal contundente e indiscutível de que o racismo segue presente na sociedade, em nossas práticas. Almeida (2019) ao discutir o racismo estrutural aponta que o racismo é uma espécie de racionalidade, uma forma de normalização e compreensão das relações, que inclusive constitui as nossas ações conscientes e inconscientes. Isto quer dizer que ainda que não nos consideremos, enquanto indivíduos conscientes, racistas, podemos operar na lógica racista quando alijamos diferentes formas de conhecer e saber de nossos programas curriculares e/ou de nossos modos de pesquisar (RIBEIRO, 2019). É preciso, então, nos colocarmos em constante reflexão (e prática) antirracista para combater este sistema de exclusão e morte.

Isto significa reconhecer outras formas de conhecimento e dar credibilidade a elas (RUFINO, 2017), o que implica numa postura crítica de engajamento à descolonização e combate ao racismo. É preciso articular outras vozes, outras epistemologias, como aquelas produzidas na diáspora africana e nos espaços de recriação das identidades negras e seus modos de vida, como os terreiros. Descolonizar não significa abandonar ou negar as escolas de pensamentos e autores do Norte, mas é abrir-se para a crítica deles, para o diálogo contextualizado, tratando da colonização, das invasões, das práticas de dominação. É uma forma de tratar nosso trauma colonial, uma forma de justiça cognitiva.

O que propomos neste texto é parte deste movimento. Nosso objetivo é pensar como elementos da cosmovisão afro-brasileira podem contribuir para a construção de outras abordagens e metodologias de pesquisa (que resistam e) que busquem romper com a tradição colonial no campo da pesquisa em educação. Para isso tomamos Exu e a encruzilhada como 
referências éticas, estéticas e epistemológicas. É a partir da noção do cruzamento que é invocada pela encruzilhada, que propomos pensar uma outra perspectiva para a pesquisa. Por fim, partindo destas concepções, apresentamos os "círculos dialógicos", frutos de nossas vivências no processo de pesquisa, como possibilidade metodológica para construção de dados no contexto da pesquisa em educação, sobretudo a partir dos registros em áudio e vídeo.

\section{A pesquisa em ciências humanas e a natureza do seu conhecimento}

Pesquisar é refletir sobre a realidade, é um fazer do pensamento humano, tentar compreender o próprio ser humano e a sua relação com o mundo, tendo em vista a complexidade dos sujeitos envolvidos nesse processo e as implicações deste ato na e para a realidade. Pesquisar é um ato ético-político, fomentador da consciência crítica para a compreensão do mundo e também forma de intervenção na realidade. Neste sentido, a pesquisa em ciências humanas é radicalmente diferente daquela feita nas ciências exatas, sobretudo no que se refere à natureza do "objeto" de pesquisa.

\footnotetext{
Nas ciências exatas, o pesquisador encontra-se diante de um objeto mudo que precisa ser contemplado para ser conhecido. $\mathrm{O}$ pesquisador estuda esse objeto e fala sobre ele. Já nas ciências humanas seu objeto de estudo é o homem. Diante dele o pesquisador não pode se limitar ao ato contemplativo, pois encontra-se perante um sujeito que tem voz, e não pode contemplá-lo, mas tem de falar com ele, estabelecer um diálogo com ele. Inverte-se, dessa maneira, toda a situação que passa de uma interação sujeito-objeto para uma relação entre sujeitos. (FREITAS, 2002, p.24).
}

Nas ciências humanas, não buscamos uma resposta exata, pronta, comprovável através de uma observação passiva diante do objeto de pesquisa, que segundo Bakhtin (2011), nas ciências exatas é "mudo" e o pesquisador que o contempla só fala dele, sobre ele. Para o autor as ciências exatas são uma forma monológica do saber e nessa relação há somente um enunciador, apenas um sujeito que fala, numa perspectiva que o autor vai chamar de 
"monologismo". O "monologismo" nega ao extremo a consciência responsiva de um "outro eu" e, assim, esse "outro" permanece apenas como objeto da consciência e não como outra consciência (BAKHTIN, 2011).

Entretanto, nas ciências humanas o pesquisador está diante de outro sujeito tão complexo quanto a si mesmo, portanto, ele não pode ser visto como coisa, embora sabemos que de certo modo, as ciências humanas ainda estão impregnadas da concepção ocidental cartesiana que muitas vezes reifica os sujeitos transformando-os em meros observáveis e, assim, nega-lhes a palavra, a própria voz-consciência. Nesta perspectiva, ela assume uma dimensão colonizadora, operando na manutenção das relações hierearquizadas, nas quais há a reprodução da lógica abissal (SANTOS, 2007). Metaforicamente falando, há nessa relação um centro (o pesquisador-metrópole) e uma periferia invadida (sujeito-colônia).

Nas ciências humanas não é possível conceber os sujeitos de modo monológico tal qual nas ciências exatas, pois a própria vida é um processo dialógico, "viver significa participar do diálogo" (BAKHTIN, 2011, p. 348). Na cena da pesquisa, momento em que pesquisador/a e participantes estão juntos, os sujeitos envolvidos são ativos, construtos do tempo e da história e não podem ser concebidos e/ou tratados como "objetos", por isso, pesquisar é um ofício que vai além de "falar sobre algo". "Conhecer implica em aceitar o abalo de nossas certezas", como bem coloca Souza e Albuquerque (2012, p.110), assim, fazer pesquisa em ciências humanas é reconhecer a provisoriedade daquilo que sabemos, dos sentidos que produzimos a partir dos nossos estudos e a própria condição do nosso inacabamento como seres humanos.

É preciso considerar, então, que não há como compreender a construção/produção do conhecimento nas ciências humanas, na pesquisa em educação, fora desta perspectiva. Nesta concepção, a pesquisa é um fazer coletivo, um "junto de", feito "com" os sujeitos e não um ato de falar sobre eles. Deste modo, tendo em vista a natureza dos "objetos" de pesquisa a que se dedica as ciências humanas, não é possível a utilização dos mesmos métodos que as ciências exatas, nem que se busque a "cientificidade própria” delas (FREITAS, 2002).

O conhecimento que os homens e mulheres podem ter sobre o mundo natural é diferente daquele que podem ter sobre si, sobre sua natureza e suas formas de criação (SOUZA \& ALBUQUERQUE, 2012). O objeto das ciências humanas não é simplesmente as ações dos seres humanos inscritos no tempo-espaço histórico ou um determinado fenômeno 
social, mas o próprio "homem", produtor de cultura, conhecimento e textos ${ }^{4}$ (BAKHTIN, 1997). Interessa-nos, então, a especificidade do pensamento das ciências humanas, os sentidos e significados dos outros, realizados e dados ao pesquisador sob a forma do texto. Independentemente de quais sejam os objetivos de uma pesquisa, só o texto pode ser o ponto de partida (BAKHTIN, 2011, p.308). Para o autor o homem tem a especificidade de expressar-se sempre, ou seja, de criar um texto (ainda que seja potencial). Quando o homem é estudado fora e independentemente do texto, já não se trata de ciências humanas, mas de anatomia, fisiologia humana, etc. (BAKHTIN, 1997, p.334).

Quanto ao pesquisador/a das ciências humanas, ele/a não pode ser concebido como um sujeito à parte da realidade investigada, que deseja compreender determinado fenômenos "desde fora". Para nós, a pretensa e falaciosa concepção de afastamento, anulação e neutralidade do pesquisador/a na construção da pesquisa não se aplica às ciências humanas; é um traço da racionalidade colonial. Enquanto pesquisadores/as estamos implicados na pesquisa tal qual os sujeitos que partilham conosco a cena da pesquisa.

O/A pesquisador/a é um sujeito concreto marcado por seu lugar social, pela sua classe, gênero, sexualidade, pelas experiências e vivências no/do contexto sociocultural que se origina e nos demais que transita. "O pesquisador do campo das ciências humanas está, portanto, transitando no terreno das descobertas, das revelações, das tomadas de conhecimento, das comunicações, das produções de sentido entre o eu e o outro" (SOUZA \& ALBUQUERQUE, 2012, p.110), por isso, não há possibilidade de "anulação" de sua presença, dos seus juízos e de sua consciência no processo de pesquisa.

Esta visão, rompe com a pretensa neutralidade no processo da pesquisa, forjada pela racionalidade colonial do ocidente ${ }^{5}$, fortemente valorizada nas ciências exatas e se permite ser afetado pelo processo da pesquisa (SOUZA \& ALBUQUERQUE, 2012). Vygostsky, de acordo com Freitas (2002), também vai considerar que o processo de pesquisa nas ciências

\footnotetext{
${ }^{4}$ A expressão "texto" refere-se aqui ao sentido de discurso, extrapolando a ideia da palavra escrita. Podemos dizer que a ideia-conceito de "texto" aqui é "aquilo que diz respeito a toda produção cultural fundada na linguagem (e para Bakhtin não há produção cultural fora da linguagem)" (STAM, 1992, p.13).

${ }^{5}$ Por racionalidade colonial do ocidente estamos nos referindo a uma cosmovisão baseada no pensamento cartesiano, na lógica abissal e na hierarquização do conhecimento, conforme aponta Santos (2007) e Quijano (1997). Nesse sentido, o ocidente (notadamente a Europa) compreende que há uma universalidade no seu discurso e conhecimento, o que apaga a diversidade dos sujeitos e do próprio conhecimento. Além disso, há no sentido que aponta Santos (2010) um esforço histórico destes povos para a manutenção do status de legítimo do pensamento do Norte ao mesmo tempo que desconsidera e invalida os conhecimentos, as epistemologias e culturas produzidas fora de suas fronteiras.
} 
humanas, bem como todo processo de produção do conhecimento e aprendizagem, são processos que se dão sempre de modo compartilhado entre sujeitos. É essencialmente um processo interacional de co-autoria, portanto, dialógico. Há sempre a partilha entre os sujeitos, uma construção coletiva/dialética dos sentidos produzidos no encontro entre sujeitos e pesquisador/a.

Sendo assim, a análise dos fenômenos sobre os quais nos debruçamos nas ciências humanas é certamente influenciada pelo nosso lugar no mundo, nossas convicções e posições como sujeitos inseridos em um tempo e lugar social histórico. O modo com que o/a pesquisador/a compreende o fenômeno que estuda não se separa do modo de avaliá-lo. Por outro lado, isso não significa fixidez no olhar, pois, ao compreender a transitoriedade dos conhecimentos, das impressões sobre sua análise e ao reconhecer seu inacabamento, o/a pesquisador/a se abre para a possibilidade de reconstrução, de mudança. Para Bakhtin (2011) o sujeito da compreensão não pode excluir a possibilidade de mudança e até de renúncia aos seus pontos de vista e posições já prontos. No ato de compreensão desenvolve-se uma luta cujo resultado é a mudança mútua e o enriquecimento (BAKHTIN, 2011, p.378).

Esta concepção é uma marca do pensamento bakhtiniano, da qual emerge uma perspectiva de pesquisa fundamentalmente alteritária, pois é sempre na (in)tensa relação do eu com o outro que se instaura o processo de compreensão e produção do conhecimento, bem como a própria vida. Nesse sentido, consideramos a pesquisa como um encontro de natureza dialógica e alteritária. Na perspectiva bakhtiniana, o que há é sempre um diálogo, interação entre sujeitos, co-autoria, processos de construção dialética e partilha. A presença do outro é condição fundamental para a construção da pesquisa em ciências humanas.

Além disso, se pensamos também desde a lógica exúlica ${ }^{6}$, a da humanização (SOUZA, 2016), é incabível considerar uma suposta anulação ou neutralidade do/a pesquisador/a na construção e desenvolvimento da pesquisa, este/a é também sujeito. O conhecimento produzido a partir do encontro entre sujeito e pesquisador/a, por sua vez, possui igualmente a dimensão dialógica, plurivocal e alteritária. É na (in)tensa relação com o seu outro que o/a

\footnotetext{
${ }^{6}$ A "lógica exúlica" é pensada a partir de princípios da ancestralidade, da continuidade entre sagrado e humano, calcada nos aspectos da figura do Orixá Exu, que recusa veemente a redução binária da existência e/ou dos múltiplos aspectos da existência humana (OLIVEIRA, 2005; SOUZA, 2016). Assim, esta proposição incorpora a noção de multiplicidade e complexidade dos sujeitos humanos reconhecendo-os como diversos, diferentes, únicos e que se fundam na alteridade, no diálogo e na comunidade.
} 
pesquisador/a (re)elabora o seu $e u$, que é por essência inacabado. "Eu tomo consciência de mim e me torno eu mesmo unicamente me revelando para o outro, através do outro e com o auxílio do outro" (BAKHTIN, 2011, p. 341). Por isso mesmo, "sem reconhecimento da alteridade não há objeto de pesquisa (AMORIM, 2001, p. 28)”.

\section{A encruzilhada como referência e possibilidade epistêmica}

A encruzilhada é um signo fundamental do pensamento e da história dos afrobrasileiros, ela é a forma cultural da matriz africana (OLIVEIRA, 2005, p. 140). É signo (e símbolo) de uma cosmovisão que não se assenta no binarismo colonial ocidental, mas se funda em uma concepção de mundo plural, que tem no "outro" parte indispensável para a existência e humanização. Como parte desta concepção temos o conceito da "ética ubuntu", discutido por Pereira et al. (2018), que se refere ao processo de ligação do sujeito ao coletivo, à "fillosofia do nós". O coletivo é um elemento civilizatório e humanizador dos africanos e, no novo mundo, funda a identidade e os modos de vida dos afro-brasileiros. Nesse sentido, a encruzilhada apresenta-se também como uma outra narrativa da história dos afro-brasileiros, já que pode admitir a polifonia de narrativas e expressa a resistência do povo negro; é uma forma de transgressão da narrativa colonial da história do continente africano e do Brasil.

A encruzilhada, bem como toda a cultura afro-brasileira, não pode ser compreendida dentro de uma visão eurocêntrica, tipicamente ocidental que tudo antagoniza (SILVA, 2005). Ela é a expressão de uma cosmovisão agregadora que permite a convivência do visível com o invisível, que não separa vida e morte, mas que vê na morte a afirmação da vida, onde passado e presente se articulam, pela circularidade, expressando o presente, onde convivem viventes e os ancestrais numa trama complexa da existência (OLIVEIRA, 2005). Nesse sentido, extrapolamos a noção da encruzilhada como apenas elemento da religiosidade afrobrasileira, onde ela é central, e a tomamos como matriz epistêmica. Isso significa dizer que o signo da encruzilhada traduz a cosmovisão afro-brasileira e expressa toda a potência desta forma de compreender (e produzir) o mundo. Ela está ligada a uma forma particular de conceber o mundo, a si e o outro, dos negros e negras da diáspora. 
Oliveira (2005) nos conta que a encruzilhada é o lugar em que se cruzam as fronteiras, onde os limites se confundem, e, por isso, é o lugar da possibilidade, da criação, do princípio. $\mathrm{Na}$ cosmovisão nagô ${ }^{7}$ é na encruzilhada que tudo se principia, de onde procede a existência, daí também a sua relação com o orixá Exu, senhor do corpo, dos caminhos, da fecundidade masculina e das encruzilhadas. Exu é o princípio de toda ação e criação de vida encarna a natureza da encruzilhada enquanto possibilidade e nos faz pensar em outras formas de ser/pensar o mundo e construir o conhecimento. Ele é a possibilidade de reinvenção do mundo, a potência para subversão da lógica colonial.

Mãe Stella de Oxossi (2010) ao se referir à encruzilhada nos conta que ela é um lugar de pausa, um momento suspenso no tempo, que leva à mudança de um estágio a outro ou, simplesmente, de uma situação a outra. Para ela, é lá também que podemos deixar aquilo que é negativo para seguirmos renascidos. Neste sentido, a encruzilhada é potente para pensarmos a insurgência decolonial, dialogando com outras epistemologias, como modo de resistir à lógica ocidental "coisificadora" ainda presente na pesquisa nas ciências humanas, um modo de nos livrarmos do "nosso" carrego colonial (RUFINO, 2017).

Ainda pensando nas palavras de Mãe Stella, pesquisar é também estar na encruzilhada já que ela gesta a novidade. É nela, enquanto território possível da existência, que o pensamento amadurece, que as certezas são confrontadas. É neste sentido, que a imagemconceito da encruzilhada, enquanto lócus de produção e enunciação do pensamento afrobrasileiro, é potente para pensarmos a pesquisa e as formas possíveis de descolonizá-la. Aderbal Moreira (Axogun do Ilê Axé Omi Aju Arô) ${ }^{8}$ se refere à encruzilhada como "palco da vida", onde tudo começa e, assim, nos oferece uma rica imagem para pensarmos o processo de produção do conhecimento nas ciências humanas, já que nosso objeto de estudo é o próprio humano.

\footnotetext{
${ }^{7}$ Ao usarmos a expressão "nagô" estamos nos referindo aos povos de origem Iorubá, região da atual Nigéria e Benim, na África. A escolha desta expressão se dá pela popularidade do termo na cultura afro-brasileira, sobretudo nas religiões afro-brasileiras, sobretudo nos candomblés, bem como na literatura antropológica e sociológica brasileira.

${ }^{8}$ Axogun (também conhecido como mão de faca) é um dos postos mais importantes do candomblé nagô (nação Ketu) e é responsável pelo rito de sacralização dos animais votivos nas cerimônias do culto. O Ilê Axé Mi Aju Orô é uma das casas mais conhecidas e tradicionais do candomblé carioca. Foi fundada por Mãe Beata de Yemojá, notória sacerdotisa e militante negra de origem baiana. A fala de Aderbal Moreira está registrada no documentário "A boca do mundo - Exu no candomblé", de Eliane Coster (2009).
} 
A encruzilhada representa um território onde co-existem múltiplos enunciados e vozes na cadeia infinita e contínua dos discursos, o encontro de diferentes visões de mundo e epistemologias. Por isso, podemos pensar nela, como alegoria para pensar o diálogo histórico, polifônico, tenso e polêmico, palco de disputas sobre o conhecimento científico. É na encruzilhada, que não é em si mesma a origem, mas encontro, que diferentes perspectivas de mundo e cosmovisões podem se encontrar. Pensar nesta perspectiva é pensar (outras) formas de conhecer, buscando uma reapropriação crítica dos referenciais do Norte como possibilidade de leitura e diálogo, orientados pelo diálogo intercultural (SANTOS \& MENESES, 2010).

São nestes aspectos que assentamos nossa compreensão da encruzilhada como possibilidade epistêmica. Lugar do princípio, da criação, da possibilidade, da novidade, uma “terceira margem” (não como resultado de uma mais outra, mas como interseção das duas produzindo o novo). A encruzilhada, como território em que início e fim convivem dialeticamente, pode ser o fim de um caminho e a reinvenção de outro. Daí a ideia da pesquisa na encruzilhada, ou melhor dizendo, das epistemologias na encruzilhada, propondo a superação do ideário colonial e a insurgência de uma epistemologia decolonial. O que propomos aqui é pensar, em alguma medida, este movimento visando o diálogo de caminhos epistemológicos aparentemente distintos para gerar outros.

Portanto, a encruzilhada nos oferece a possibilidade de reinvenção do mundo e pode proporcionar a construção de outras epistemologias, outros modos de construir a pesquisa (RUFINO, 2017). Como possibilidade epistemológica, ela se apresenta como forma de interpretar e orientar a pesquisa, bem como a própria realidade uma vez que ela expressa a complexidade da existência humana e a sua inscrição no mundo, na grande temporalidade. É na encruzilhada que se instala a possibilidade de um novo caminho, cruzado com tantos outros e materializando a inversão da lógica ocidental hierarquizante dos conhecimentos e saberes. Assim, o caráter múltiplo e polifônico da encruzilhada rompe com uma visão eurocêntrica do conhecimento, que se expressa através de um discurso unívoco, monológico, tomando emprestada uma expressão de Bakhtin (2011).

Exu e Bakhtin: o diálogo como elemento estuturante para uma pesquisa na encruzilhada 
Aproximar Exu e Bakhtin faz parte do empreendimento decolonial a que temos nos dedicado para pensar a pesquisa em educação e este encontro, seguramente, tem sua essência maior no diálogo. Bakhtin e Exu, de certo modo, dividem o mesmo fundamento na/para a compreensão dos sujeitos como falantes, essencialmente dialógicos que pela/na linguagem corporificam dialeticamente as relações sociais e se (re)constroem mutuamente no cotidiano. "A vida é dialógica por natureza. Viver significa participar do diálogo: interrogar, ouvir, responder, concordar, etc." (BAKHTIN, 2011, p. 348). O diálogo, nesse sentido, é o fundamento deste assentamento epistemológico de Exu e Bakhtin, é a unidade orgânica para a alteridade.

Para Bakhtin (2011) o diálogo se expressa, inclusive, nos próprios corpos, já que “o homem participa inteiro e com toda a vida: com os olhos, os lábios, as mãos, a alma, o espírito, todo o corpo, os atos. Aplica-se totalmente na palavra, e essa palavra entra no tecido dialógico da vida humana (...)” (BAKHTIN, 2011, p. 348). Exu é esta força propulsora que move o universo e a palavra. Exu, como o senhor do corpo e da fala, é o combustível deste movimento, já que na ética e cosmovisão nagô o homem não está separado de sua palavra.

Assim, extrapolando a noção bakhtiniana de diálogo e recriando-a na potência de Exu podemos conceber a encruzilhada como o território do diálogo. No diálogo, há encontro e cruzamento de diferentes posições, pensamentos, horizontes, vozes e sujeitos que numa (in)tensa interação, experimentam as relações de poder, vão se construindo pelo diálogo. $\mathrm{O}$ diálogo, então, é a unidade indipensável para a construção social e subjetiva dos humanos. Isto porque a linguagem só existe socialmente e, na teoria bakhtiniana, as vozes sociais que engendram os discursos são definidoras do próprio processo social no qual se dá o diálogo. São essas vozes múltiplas e diversas que constituem cotidianamente o tecido social, as práticas culturais, os modos de vida. A palavra torna-se, então, constituinte da própria realidade e dos homens. O homem é a palavra (diálogo), inserida em um tempo e espaço histórico (con)vivendo com seus outros. O sujeito humano é a totalidade das relações sociais que a própria palavra materializa produzindo outros sentidos, desvelando a consciência de si, do outro e do mundo.

Esta é a ponte que une Exu e Bakhtin. Exu, na cosmovisão afro-brasileira, é o orixá do diálogo, é aquele que estabelece a comunicação, tanto entre o sagrado e os humanos, como entre os homens. Exu é o senhor da ordem, aquele que proporciona as condições necessárias 
para a nossa comunicação, que fecunda nossos diálogos, sempre prenhes de respostas e continuidade. Em Exu, assim como em Bakhtin, a palavra é aquilo que me liga ao outro. As relações sociais só podem se constituir de modo orgânico pelo diálogo, na partilha da palavra. Exu é quem toma a palavra como lócus da construção do sujeito e inaugura outra possibilidade para pensar o processo dialógico como um projeto de construção de si, do outro e do mundo. É ele, por meio da palavra, que nos conduz em direção ao outro, à alteridade.

A dialogicidade, tanto em Exu quanto em Bakhtin, é a condição fundamental para a produção de sentidos sobre/na realidade e para a construção dos sujeitos, de suas subjetividades e consciências, culturas, ritos, mitos e história. Por isso, cruzar essas duas concepções é a materialização da insugência decolonial. O diálogo entre Exu e Bakhtin faz com que pensemos sobre as possibilidades de fazer outras leituras dos clássicos, a partir de uma perspectiva decolonial; aponta a construção de uma leitura desde de dentro, do ponto de vista dos sujeitos que estão lutando por um espaço de legitimidade das outras formas de ler/pensar/conceber o mundo, a realidade e o conhecimento.

É próprio de Exu a novidade, inaugurar caminhos e possibilidades ainda não vistas, pensadas, por isso, este encontro é mais um caminho desta encruzilhada, mais uma conta que vai sendo colocada no grande fio do conhecimento. É no encontro de outras vozes, na polifonia, na/pela diversidade, que vamos colorindo e refundando o processo de construção de uma outra pesquisa, descolonizada, feita na encruzilhada. Fazemos isto na intenção de apresentar os diferentes caminhos teóricos, filosóficos, metodológicos que vão constituindo essa encruzilhada decolonial.

Por fim, tomando emprestado um termo do cinema, anunciamos que é por estas lentes e planos que desejo pensar esse projeto epistemológico e estético para a pesquisa. Bakhtin e Exu na recriação da encruzilhada, traçando outras linhas Sul-Norte para a compreensão e construção de um pensamento polifônico, que rompa com o monologismo colonial e que se abra, permanentemente, ao outro, à alteridade. Mais que isso, Exu e Bakhtin anunciam a possibilidade da desconstrução da hegemonia eurocêntrica do conhecimento e isto implica na construção de um projeto teórico-metodológico, político e ético, que esculhambe com os dualismos da colonialidade e amplie as nossas possibilidades de conceber e ler o mundo. A descolonização, nesse sentido, exige a presença de outras epistemologias na leitura crítica do pensamento do ocidente. 


\section{Na encruzilhada há muitos caminhos}

O paradigma da ciência moderna ocidental, ao longo dos séculos, tem requerido para si o estatuto de único legítimo. Para defender sua hegemonia a ciência moderna não se permitiu conviver com nenhuma outra forma de produção do conhecimento e nenhuma outra forma de saber, conforme nos conta Andrade (2018), e isso levou a um verdadeiro epistemicídio (CARNEIRO, 2005). Na prática, isto significa a morte, a interdição e a invisibilidade de todas as outras visões de mundo e modos de produção do conhecimento fora dos limites do Norte. Por meio da colonialidade (QUIJANO, 1997), foram elaboradas inúmeras estratégias de articulação para o ocultamento e eliminação dos saberes produzidos pelos povos originários (ANDRADE, 2018). Tal fato, em nossa leitura, é a reafirmação do pacto narcísico da branquitude, como bem coloca Cida Bento (2002), uma vez que o homem branco ocidental se pensa como universal, como norma e, desse modo, enxerga tudo que é diferente de si mesmo como desviante e inferior.

Rufino (2017) afirma que o paradigma do conhecimento ocidental, que se requer como único legítimo, é indefensável e evoca Exu e a encruzilhada como potências éticas e epistemológicas para a emergência de um paradigma cosmopolita, buscando reconhecer e credibilizar outras perspectivas de conhecimento, criadas a partir de outros saberes. Um movimento insurgente no sentido da superação da nossa condição colonial, abissal, no qual também nos situamos. Exu e a encruzilhada são nossos aportes epistemológicos.

Historicamente estivemos presos a uma tradição eurocêntrica colonial, mas se os humanos são diferentes, se produzem culturas e subjetividades distintas, não é possível pensar que há apenas uma forma de ver o mundo e compreender os fenômenos sociais, sobretudo no campo da educação. Este é o nosso ponto de partida neste texto. Há muitos caminhos nesta encruzilhada. Contudo, para pensarmos uma pesquisa que se deseje decolonial e antirracista é preciso repensar as nossas opções metodológicas, uma vez que grande parte das formulações para construção de dados que utilizamos ainda obedecem à lógica colonial. É preciso reaprender, romper com os formalismos e teorizações emprestadas, nos dizeres de Antônio Candido (2000). Precisamos, enquanto pesquisadores e pesquisadoras do campo da educação, 
nos debruçarmos na reconstrução, releitura e superação de instrumentos metodológicos forjados no bojo das tradições coloniais academicistas e hierarquizantes.

Quanto a isso Paulo Freire (1995, p. 60) também nos provoca apontando que não é possível reler o mundo se não melhoramos os velhos instrumentos, se não os reinventamos. Não podemos buscar construir uma pesquisa que se coloca em uma perspectiva de humanização usando os mesmos caminhos metodológicos construídos na/pela colonialidade. É preciso exulizar o processo. Como pesquisadores/as somos desafiados eticamente a humanizar o processo de pesquisa, a construir um olhar dialógico, capaz de conviver com as distintas humanidades dos sujeitos envolvidos em nossas pesquisas e ouvir sua palavra, na escuta ativa, solidária. Quando ouvimos o enunciado do outro, nos colocamos na direção deste outro (FREITAS, 2003). Isso é uma tarefa política, ética e estética, sobretudo em tempos em que as liberdades individuais e democráticas se encontram ameaçadas por um processo de precarização da liberdade e do trabalho, inclusive o intelectual. Exige, de antemão, uma posição de abertura, de questionamento das tradições impostas pelas formas coloniais, da individuação, da dissolução do coletivo.

Assim, (re)criar instrumentos metodológicos que nos auxiliem na construção de nossas pesquisas é uma demanda concreta da justiça cognitiva, especialmente quando estes estudos estão ligados aos fenômenos educativos fora dos temas eurocentrados. Acreditamos, apoiados em Gomez et al. (2014), na reconstrução de práticas de pesquisa contextualizadas para não perder os referenciais culturais da comunidade (a qual se encontra instalada o processo da pesquisa) e evitar assim a invasão cultural. Diante disso, propomos os chamados "círculos dialógicos" inspirados no pensamento de Mikhail Bakhtin (2011), sobretudo nas categorias diálogo e alteridade, além do pensamento afro-brasileiro a partir da encruzilhada e Exu, buscando também nos apoiarmos em Paulo Freire (1967) quando da criação dos círculos de cultura.

\section{A concepção dos círculos dialógicos}

Para a concepção dos círculos dialógicos nos inspiramos em três grandes categorias epistêmicas, se assim pudermos considerar: a cosmovisão afro-brasileira, os círculos de 
cultura de Paulo Freire (1989) e o pensamento dialógico de Mikhail Bakhtin (2006; 2011). Este movimento de (re)elaboração e síntese, está dentro da concepção circular da lógica exulíca que buscamos ter como orientadora desta perspectiva teórico-metodológica. Apoiados em Bakhtin (2011), entendemos que todo conhecimento é uma construção discursiva, é a continuação do grande fluxo histórico dos discursos que é infinito e acabado. Nesta perspectiva, o conhecimento que produzimos agora, com determinados acabamentos, são provisórios, são abertamente um diálogo com o que já se produziu antes. É a perspectiva circular na prática, é Exu.

A palavra círculo, do latim circulus, significa "redondeza" e isso nos permite pensar tanto no espaço físico quanto metafísico pelo qual pode transitar saberes, experiências, sentimentos, dores, alegrias e incômodos. Desse modo, a ideia de círculo nos oferece uma boa "imagem" para a idealização/realização de encontros na pesquisa em educação. O círculo dialógico, neste contexto, é um instrumento para construção de dados que necessariamente está fundado no encontro e diálogo do pesquisador com os sujeitos. O círculo foi concebido para trazer os sujeitos da pesquisa para o centro do processo, já que ele, experimentado em outros espaços, como os terreiros e na capoeira, pode proporcionar uma maior abertura dos sujeitos ao processo vivenciado. Além disso, ele pode potencializar a ideia de pertencimento e conferir aos sujeitos autoestima, confiança, aconchego, solidariedade e compromisso com os outros e com as situações na cena dialógica em que se desenrola a pesquisa.

Estes aspectos são elementos que constituem também a organização da cultura e cosmovisão afro-brasileira, a primeira grande inspiração para a construção dos círculos dialógicos. De acordo com Oliveira (2009) a cultura e o pensamento afro-brasileiro, calcados nos princípios da ancestralidade, são circulares, não admitem compreensões hierárquicas de mundo, tampouco verticaliza as relações, embora tenha em si delimitações explícitas de identidades sociais. O círculo, neste sentido, possui uma dimensão ritualística, como se observa na organização dos ritos das religiões afro-brasileiras e das "Casas de Santo", como também são chamados os terreiros de religiões afro-brasileiras.

O círculo é então um signo da ancestralidade afro-brasileira e representa a circularidade dos sabres do povo negro na medida em que se presta a ser um espaço da partilha do conhecimento ancestral. Pensando no círculo dentro da casa de Santo, por exemplo, ele é a representação da igualdade entre os sujeitos ali reunidos. Na roda todos e todas, independentes da posição que ocupam fora do terreiro, são iguais. Ali não há ninguém 
à frente ou atrás do outro, estão ao lado. Nesta disposição, todos ali, na roda, como iguais: a manutenção do poder e da resistência do povo negro. Elo. Ligação. Ancestralidade.

Em círculo o povo negro resiste ao racismo, ao genocídio, à intolerância e a violência religiosa, sendo uma forma de se organizar para resistir. Foi também em círculo que o povo negro perpetuou sua história, cultura e religiosidade, sobretudo por meio da palavra falada, na tradição oral. Até hoje os cultos afro-diaspóricos são chamados de "giras" e/ou "rodas de Santo" e são realizados literalmente em círculos preservando essa tradição secular. O círculo é parte da essência de Exu, aquilo que revive e contemporiza o pensamento negro, afrobrasileiro, a cultura de resistência.

Refletindo ainda sobre os aspectos míticos do círculo, na tradição afro-brasileira, pensamos em Oxum, orixá da fertilidade, da riqueza, da prosperidade, do amor, é a senhora dona dos ventres das mulheres e da fecundidade. Inspirados em Oxum, podemos conceber o círculo como aquilo que gera, que dá à luz a palavra. O círculo como "útero" do diálogo, de onde vem a escuta atenta ao outro, bem como daquilo que interroga, provoca, desafia, interpela e dá origem ao novo.

A palavra, como aquilo que cruza todas as esferas da existência humana e da experiência social (BAKHTIN, 2006), também possui esta dimensão cíclica; não em uma perspectiva de repetição, mas em sua natureza dialógica que sempre pede uma contrapalavra e, assim, é capaz de gerar outros sentidos. A circularidade da palavra como genitora da produção de sentidos novos sobre aquilo que se pronuncia, iniciando um ciclo responsivo, dialógico.

Retomando Paulo Freire (1967), como nossa segunda grande categoria epistêmica, concordamos que no círculo não há o que sabe mais que ensina o que sabe menos, os saberes são (com)partilhados. No círculo, não estão só os sujeitos da pesquisa e o pesquisador, mas também todos os outros e suas experiências que são trazidas em cada sujeito. Desse modo, ao compartilhar sentidos e experiências, os sujeitos, o/a pesquisador/a, transformam-se mutuamente e, por isso, o círculo é uma possibilidade de intervenção pedagógica, de formação. Neste sentido, acreditamos que os círculos dialógicos guardam, de algum modo, parte do pensamento freireano que nos ensina que toda prática diferente de uma prática dialógica seria uma forma de violação de subjetividades e mais que isso, de colonização (FREIRE, 1967). Assim, a preocupação na construção dos encontros com os sujeitos na pesquisa é o reconhecimento de suas subjetividades, histórias, experiências, trajetórias e 
culturas. Não é possível pensar em descolonização se não priorizamos antes o reconhecimento do outro como igual, se não os ouço, se não os tenho como coautores do processo.

$\mathrm{O}$ pensamento de Bakhtin, nossa terceira categoria epistêmica, funda-se essencialmente no princípio dialógico da interação entre sujeitos. Nessa perspectiva, os sujeitos são vistos como a voz ativa da cena da pesquisa, inclusive construindo-a como coautores. Para Freitas (2009, p. 29) "considerar a pessoa investigada como sujeito implica compreendê-la como possuidora de uma voz reveladora da capacidade de construir um conhecimento sobre sua realidade que a torna coparticipante do processo de pesquisa”. Assim, o contato direto com os sujeitos da pesquisa, nesta abordagem, pode proporcionar encontros mais horizontais (resguardando as especificidades e responsabilidade do pesquisador) que podem ser capazes de revelar muito mais do processo, também formativo, na/da cena da pesquisa. De modo geral, os círculos dialógicos têm uma pretensão também formativa, visto que há neste processo possibilidades para a formação dos sujeitos envolvidos no processo de pesquisa, além da formação do/a pesquisador/a.

Nesta perspectiva, expandimos os sentidos sobre o círculo, ele deixa de ser visto/compreendido como apenas uma organização espacial e passa a ser signo da ancestralidade, da construção histórica da resistência do povo negro, partilha e preservação de saberes, inspirando-nos a pensar em outros caminhos para as nossas pesquisas. Recorrer ao círculo, no interior da lógica exúlica, é já trazer à concretude outras epistemologias, buscando a justiça cognitiva para com o pensamento ancestral do povo negro deste país.

\section{Os círculos dialógicos na cena da pesquisa}

A partir das concepções que apresentamos ao longo do texto, tomando a lógica exúlica como orientadora do processo de pesquisa, apresentamos aqui uma experiência de pesquisa de mestrado realizada pelos autores do texto entre os anos de 2017-2019. O objetivo desta pesquisa foi pensar as potências oferecidas pelo cinema nacional para a educação das relações étnico-raciais, ao tratar da cultura e a religiosidade afro-brasileira, no processo de formação docente. O campo para a construção dos dados foi realizado durante um "ciclo de formação" 
contando inicialmente com dez licenciandos dos cursos de Pedagogia, Letras, História e Geografia.

O objetivo do ciclo de formação era formar os licenciandos para a educação das relações étnico-raciais a partir do cinema; com isso, todo processo se desenvolveu a partir dos filmes. Foram realizados sete encontros organizados em três grandes blocos temáticos que nomeamos como: "Cinema e formação docente", "Olhando para o outro: o povo negro na sociedade brasileira" e "Cultura afro-brasileira e formação docente”. A partir destes temas, trabalhamos com oito filmes, entre curtas e longas-metragens. Os encontros, respeitando os princípios éticos da pesquisa, foram gravados em áudio e vídeo e posteriormente analisados.

Nos encontros semanais, após a exibição do filme, os sujeitos foram convidados a sentar-se em roda, de modo em que todos pudessem se ver, incluindo o pesquisador, e começavam, de modo bastante espontâneo, a discussão sobre o filme. Este processo era fomentado inicialmente por uma pergunta-guia feita aos sujeitos pelo pesquisador. A questão era elaborada a partir dos objetivos da pesquisa em diálogo com o bloco temático da semana. O debate acontecia de modo bastante dinâmico e respeitoso, aspectos ao qual creditamos ao círculo. Em nossa experiência, foi possível perceber que o círculo favoreceu a criação de uma relação sincera e, de certo modo, afetuosa entre os participantes (e com o pesquisador). Isto possibilitou uma relação mais horizontal, fora dos moldes coloniais de "coleta de dados" com as quais estamos já "familiarizados", rompendo com o que Gomez (2014) chama de "colonização do outro".

Durante todo o processo, o pesquisador além de observar, tomava notas, fazia provocações e participava do processo, já que nesta abordagem o papel do pesquisador vai além da observação e registro. Ele está inserido no processo, se deixa afetar, assim como os outros sujeitos. No entanto, mesmo envolvido no processo, o pesquisador, do seu lugar exotópico (BAKHTIN, 2011), se mantém ciente de seu papel e função enquanto sujeito interpretante daquele fenômeno. As notas de campo, a observação, a escuta atenta e o diálogo são estratégias importantes pelos quais o pesquisador, nesta abordagem, vai registrando o processo para depois analisá-lo.

Cada encontro começava com a retomada das discussões e dos filmes anteriores, o que proporcionava aos sujeitos a possibilidade de criação de uma visão circular, não-fragmentada do processo. Os relatos dos sujeitos sobre este aspecto sempre foram no sentido de que a reflexão se alongava para além do encontro e que este processo de retomada era uma espécie 
de "acabamento" de suas reflexões. Com isto, conseguimos, na prática, pensar e agir na lógica exúlica, da encruzilhada. Processo que se estendeu à análise dos dados, no qual o pesquisador pôde construir uma visão processual e holística dos fenômenos, não tomando um evento isolado como expressão do todo. Nesta perspectiva, fizemos uma análise orientados pela circularidade, pelo diálogo, pela valorização da voz dos sujeitos e pelo trato ético com os seus discursos.

Ao longo dos encontros foi possível perceber que os círculos eram mais do que um arranjo para construção de dados para uma pesquisa. Era, antes, um espaço de formação, cumprindo o que desejamos quando pensamos na pesquisa, no sentido freireano, como possibilidade de transformação, como ato responsável. Nesse sentido, a riqueza do círculo dialógico não está em sua estrutura, relativamente simples, mas no processo que ele potencializa, nas relações que permite serem construídas entre os sujeitos (e pesquisador) e na possibilidade de seus deslocamentos e aprendizagens. O círculo assumiu um caráter (trans)formador do sujeito, onde diálogo e alteridade são fundamentos. Esta foi uma marca de destaque nos discursos dos sujeitos que participaram da pesquisa. Cada um, ao seu modo, revelou ter sido afetado por este processo, relataram como eram antes e depois dos círculos, de como haviam sido deslocados. Revelaram também que os círculos foram espaços importantes para repensar suas concepções acerca da cultura afro-brasileira, que ampliaram seus repertórios e visões de mundo, despertando-os para uma prática antirracista. Tudo isso revela a potência dos círculos, para além de um dispositivo de construção de dados, consolidando-o como parte de um outro modo de conceber e fazer pesquisa em educação.

Destacamos, por fim, que os círculos dialógicos possuem, de certa forma, uma similaridade com outras estratégias de construção de dados, como os círculos de cultura e os chamados "grupos focais". Entretanto, destacamos que os círculos dialógicos guardam especificidades que os diferenciam, sobretudo em sua concepção e na questão do tratamento ao sujeito da pesquisa. Há nos círculos dialógicos, apoiando-nos em Bakhtin $(2006 ; 2011)$ e na lógica exúlica, uma centralidade no diálogo trazendo a voz ativa dos sujeitos para o centro do processo. A circularidade e a alteridade, pensada desde as potências de Exu e da encruzilhada, são os fios condutores do processo e revelam a dimensão potente da cosmovisão afro-brasileira para pensar a pesquisa. Portanto, os círculos dialógicos são expressões de uma pesquisa gestada na encruzilhada, são possibilidades práticas de ruptura com a lógica colonizadora ocidental na pesquisa em educação. 


\section{Algumas considerações}

A encruzilhada como referência epistemológica, calcada na cosmovisão afrobrasileira, é sem dúvida uma subversão à lógica colonial ocidental. É a busca, na prática, pela descolonização dos nossos conhecimentos. Com isso estamos dizendo que pensar a pesquisa em diálogo com outras matrizes de pensamento, ampliando nossos repertórios intelectuais, culturais é um exercício de justiça cognitiva, um gesto de reparação histórica. Reconhecer que há outras possibilidades de compreensão do mundo e de produção do conhecimento é o início deste processo que, certamente, não se encerra em si mesmo.

Conceber uma pesquisa na encruzilhada, como tratamos neste texto, é antes de tudo uma prática antirracista, uma contrapalavra à lógica da colonialidade e, sobretudo, um passo em direção à democratização epistêmica dos espaços intelectuais de produção do conhecimento. É pensar na restituição simbólica do reconhecimento de saberes produzidos fora dos limites do pensamento hegemônico ocidental. Fazer isto é mergulhar em um oceano de possibilidades para a pesquisa em educação, enriquecendo ainda mais nossas perspectivas de conhecimento e potências de ação.

Por fim, reafirmamos, que não é nossa pretensão negar os referenciais vindos do Norte, sobretudo porque reconhecemos que nem todo conhecimento vindo de lá reproduz o ideário colonialista ocidental. O que estamos questionando aqui é a necessidade de pensar uma pesquisa em educação fora do monologismo colonial, desde o nosso lugar. É uma urgência do nosso tempo trilhar caminhos na direção de uma ecologia de saberes (SANTOS, 2010). Os círculos dialógicos apresentados neste texto, inclusive, são experiências gestadas nesta lógica e revela que é possível este exercício. Ao tomarmos a encruzilhada como referência epistemológica estamos antes de qualquer coisa defendendo a humanização dos nossos conhecimentos e os colocando a serviço da democratização do saber e isto é Exu.

\section{Referências}

Revista Devir Educação, Lavras, vol.4, n.2, p.291-313 jul./dez., 2020. 
ALMEIDA, Silvio. Racismo estrutural. São Paulo: Selo Sueli Carneiro; Pólen, 2019.

AMORIM, Marília. O pesquisador e seu outro: Bakhtin nas ciências humanas. São Paulo: Musa Editora, 2001.

ANDRADE, Michely Peres de. Lélia Gonzalez e o papel da educação para o feminismo negro brasileiro. Interritórios - Revista de Educação da UFPE, Recife, v.4, n.6, p. 75-92, 2018.

BAKHTIN, Mikhail. Estética da Criação Verbal (Tradução de Paulo Bezerra). $6^{\circ}$ ed. São Paulo: Martins Fontes, 2011.

BAKHTIN, Mikhail/VOLOCHÍNOV, Valentín N. Marxismo e Filosofia da Linguagem (Tradução de Michel Lahud e Yara Frateschi). 12 ed. São Paulo: Hucitec, 2006.

BENTO, Maria Aparecida da Silva. Pactos narcísicos no racismo: branquitude e poder nas organizações empresariais e no poder público. 2002. 185f. Tese (Doutorado em Psicologia Escolar e do Desenvolvimento Humano) - Instituto de Psicologia, Universidade de São Paulo, São Paulo, 2002.

CANDIDO, Antônio. Literatura e sociedade. 8 ed. São Paulo: Publifolha, 2000.

CARNEIRO, Aparecida Sueli. A construção do outro como não-ser como fundamento do ser. 2005. 339f. Tese (Doutorado em Educação) - Faculdade de Educação, Universidade de São Paulo, São Paulo, 2005.

FREIRE, Paulo. À sombra desta mangueira. São Paulo: Olho D’água, 1995.

FREIRE, Paulo. Educação como prática da liberdade. 1.ed. Rio de Janeiro: Paz e Terra, 1967.

FREITAS, Maria Teresa A. A abordagem sócio-histórica como orientadora da pesquisa qualitativa. Cadernos de Pesquisa (Fundação Carlos Chagas), São Paulo, v. 1, n.116, p. 21-39, jul. 2002.

FREITAS, Maria Teresa A. A perspectiva sócio-histórica: uma visão humana da construção do conhecimento. In: FREITAS, M. T.; SOUZA, JOBIM E SOUZA, S; KRAMER, S. (Org.). Ciências Humanas e Pesquisa: Leituras de Mikhail Bakhtin. São Paulo: Cortez Editora, 2003, p. 26-38.

FREITAS, Maria Teresa A. A pesquisa de abordagem histórico-cultural: um espaço educativo de construção de sujeitos. Teias, [S.1.], v. 10, n.19, p. 1-12, jul. 2009.

FREITAS, Maria Teresa A. Linguagem, consciência e vida humana no pensamento de Bakhtin e Vygotsky. In: FREITAS, M. T A; RAMOS, B. S. S. (Orgs). Bakhtin partilhado. Curitiba: Editora CRV, 2017, p. 13-28. 
GOMEZ, Margarita; TAVEIRA, Adriano S. N. E.; APOLINARIO, Joseneide; AGUIAR, Alessandra D.; BIOTO, Luis Carlos. Pesquisas e práticas educacionais com o círculo de cultura. Reunião da ANPED - SUL (ANPEDINHA), São João Del Rei, 2014.

OLIVEIRA, Eduardo D. Epistemologia da Ancestralidade. Entrelugares: Revista de Sociopoética e Abordagens Afins, [S. 1.], v. 1, p. 1-10, 2009.

OLIVEIRA, Eduardo D. Filosofia da Ancestralidade: corpo e mito na filosofia da educação brasileira. 2005. 353 f. Tese (Doutorado em Educação) - Faculdade de Educação, Universidade Federal do Ceará, Fortaleza, 2005.

OLIVEIRA, Eduardo. Epistemologia da Ancestralidade. Entrelugares: Revista de Sociopoética e Abordagens Afins, [S. 1], v. 1, p. 1-10, 2009.

ORIEL PEREIRA, Artur; SANTIAGO, Flavio; LIMA SOUZA, Ellen Gonzaga. Ubuntu: acolhimento ancestral e inquietações feministas negras à educação de bebês e crianças pequenas em creches e pré-escolas. Revista Teias, [S.1.], v. 19, n. 53, p. 314-329, jul. 2018.

OXÓSSI, Mãe Stella de. Balaio de Ideias: Na encruzilhada da vida. Jornal "A TARDE", Salvador, 23 de maio de 2012, Blog Mundo Afro (online). Disponível em:

QUIJANO, Aníbal. Colonialidad del Poder, Cultura y Conocimiento en América Latina. Anuário Mariateguiano, Lima, v. 9, n. 9, p. 227-238, ago.1997.

RIBEIRO, Djamila. Pequeno manual antirracista. $1^{\circ}$ ed. São Paulo: Companhia das letras, 2019.

RUFINO, Luis Rodrigues. Exu e a Pedagogia das Encruzilhadas. 2017. 233 f. Tese (Doutorado em Educação) - Programa de Pós-Graduação em Educação, Faculdade de Educação, Universidade do Estado do Rio de Janeiro, Rio de Janeiro, 2017.

SANTOS, Boaventura de Sousa. Para além do pensamento abissal. Novos Estudos CEBRAP, [S.1], n. 79, p. 71 -94, nov. 2007.

SANTOS, Boaventura de Sousa; MENESES, Maria Paula (Orgs.). Epistemologias do Sul. $2^{\circ}$ ed. São Paulo: Cortez, 2010.

SILVA, Nelson Fernando Inocêncio. Africanidade e religiosidade: uma possibilidade de abordagem sobre as sagradas matrizes africanas na escola. In: Educação anti-racista: caminhos abertos pela Lei Federal no 10.639/03. Secretaria de Educação Continuada, Alfabetização e Diversidade. - Brasília: Ministério da Educação, Secretaria de Educação Continuada, Alfabetização e Diversidade, 2005. 121-132p.

SOUZA, Ellen de Lima. Experiências de infâncias com produções de culturas no Ilê Axé Omo Oxé Ibá Latam. 2016. 179 f. Tese (Doutorado em Educação) - Departamento de Educação, Universidade Federal de São Carlos, São Carlos, 2016. 
SOUZA, Solange Jobim e.; ALBUQUERQUE, Elaine. D. Porto e. A pesquisa em ciências humanas: uma leitura bakhtiniana. Bakhtiniana - Revista de Estudos do Discurso, [S.1], v. 7, n.2, p. 109-122, nov. 2012.

STAM, Robert. Bakhtin: Da teoria literária à cultura de massa (Tradução: Heloísa Jahn). Editora Ática: São Paulo, 1992.

Recebido em 02/07/2020

Aprovado em 30/09/2020 